\title{
Agency Problem And The Value Of Conglomerates
}

Yuri Khoroshilov, University of Ottawa, Canada

\begin{abstract}
Empirical studies show that a large portion of the diversification discount can be explained by controlling for firm-specific characteristics. Although these studies leave no doubt that there is a self-selection component in firm's decision to diversify, the failure to explain the entire discount implies that some conglomerates destroy value and raises a question: why firms choose to diversify and what prevent them from value-increasing divestitures. This paper provides an answer to this question. It argues that the agency cost in a conglomerate is positively related to the number of divisions with good investment opportunities. Therefore, benefits of conglomeration offset agency costs for conglomerates with a number of bad divisions and make diversification profitable for bad firms. However, when investment opportunities of some divisions improve, the agency cost increases and offsets the benefits of diversification. Unfortunately, if investors cannot correctly price all of the conglomerate's divisions, the conglomerate cannot receive the fair price for its good divisions and, therefore, cannot implement value-increasing divestitures. As a result, the paper predicts a negative relationship between the age of the conglomerate and the diversification discount, while a failure to control for the self-selection bias may lead to an incorrect conclusion that this relationship is positive. By looking at the exogenous shocks to the economy, the paper also predicts more refocusing activities and greater value-distortion of diversification during economic booms.
\end{abstract}

Keywords: conglomerates, diversification and divestiture, agency problem

\section{$1 \quad$ INTRODUCTION}

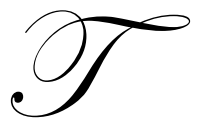

he reasons for firms' decisions to diversify and the effects of diversification on their performance have attracted researchers for the past ten years. There is evidence (see Lang and Stulz (1994), Servaes (1996), Berger and Ofek (1995)) that conglomerates are traded at a discount of about 15\% relative to the portfolio of single segment firms that are similar to the conglomerate's divisions. One of the reasons for such a discount is the internal capital markets inefficiency (or capital misallocation among divisions of a conglomerate) documented by Rajan, Servaes and Zingales (2000), Scharfstein (1998), Lamont (1997) and Shin and Stulz (1998) and modeled by Rajan, Servaes and Zingales (2000), Scharfstein and Stein (2000) and Goel, Nanda and Narayanan (2004) ${ }^{1}$. Another reason can be the difference in investment opportunities that exists between divisions of a conglomerate and single segment firms (Maksimovic and Phillips, 2002). Finally, Villalonga (2004a) argues that the documented diversification discount may be due to the poor definition of a "segment" provided by the

\footnotetext{
${ }^{1}$ Rajan, Servaes and Zingales (2000) present a model that predicts that the larger the differences among divisions are, the more resources are allocated toward most inefficient divisions. Scharfstein and Stein (2000) develop a model of capital allocation in a conglomerate in which divisional managers may be engaged in the rent-seeking activities. In order to prevent divisional managers from rent-seeking behavior, headquarters need to bribe them and the size of these bribes is larger for managers of bad divisions. The existence of a conflict between the headquarters and shareholders prevents cash bribes and makes bribes to take the form of an extra investment. Such investment misallocation toward bad divisions results in diversification discount. Goel, Nanda and Narayanan (2004) present a model in which manager's desire to improve market perception of his abilities leads to an overinvestment in divisions with more informative cash flows.
} 
Statement of Financial Accounting Standards and used by COMPUSTAT. She shows that the use of an alternative definition results in diversification premium ${ }^{2}$.

There is also evidence (see Lang and Stulz (1999), Hyland (2002) and Chevalier (2004)) that diversifying firms perform poorly prior to conglomeration and that there is a positive market reaction on diversifying acquisitions $\left(\right.$ Graham, Lemmon and Wolf (2002)) ${ }^{3}$. Villalonga (2004b) estimates how firms' characteristics affect their decision to diversify and shows that taking these estimates into account makes diversification discount statistically insignificant ${ }^{4}$. Lamont and Polk (2002), on the contrary, by looking at how the firm value is affected by the exogenous changes in industry characteristics, show that diversification destroys value. Therefore, these studies lead to a conclusion that although self-selection bias can explain a part of the diversification discount, diversification can be value-destroying. This leaves us with a question: why do single segment firms choose to diversify and what prevents conglomerates from value-increasing divestitures?

This paper provides an answer to this question. It presents a model of corporate scope that is consistent with the abovementioned evidence of capital misallocation, diversification discount and self-selection. By looking at diversification and divestiture decisions from a new dynamic setting, we are able to integrate the two competing approaches which try to explain the diversification discount. Our model is consistent with both the empirical evidence of value-destroying investment misallocation in conglomerates and with the evidence of the self-selection bias in firms' decisions to diversify.

The model presented in this paper is based on four premises. The first premise deals with the production technology. We assume that production units (single segment firms or conglomerate divisions) can have different investment opportunities ("bad" or "good") that can change over time according to some exogenously specified stochastic rule (same for all units). Furthermore, we assume that diversification produces some value (e.g., through greater operating efficiency, greater debt capacity, or lower taxes). Second, we assume that due to the asymmetric information regarding the type of each of the conglomerate's divisions the market cannot correctly price a division. The third premise deals with managers' utility functions. We assume that managers derive utility from having more resources under their control. Furthermore, since managers of single segment firms are more independent than divisional managers and have greater control over the cash flow produced, their utility from cash flows is greater than that of divisional managers. Finally, we assume that contracting is incomplete. In particular, similar to the Scharfstein and Stein (2000), we assume that managers derive their utility only from resources under their control. As a result, funds rationing and a threat of firing are the only instruments of solving principal-agent conflicts. Since working in a bad unit provides managers with lower utility, we assume that a manager who has been fired can only find a job in a bad single segment firm.

The intuition behind our model is the following. First, we show that lower enjoyment of a cash flow by divisional managers results in more severe principal-agent conflict and leads to capital misallocation and crosssubsidization in conglomerates (i.e., underinvestment in good divisions and overinvestment in bad divisions). Namely, to prevent managers of bad divisions from quitting their jobs, their expected utility should be equal to the expected utility of managers of bad single segment firms. To achieve this, headquarters of a conglomerate should provide bad divisions with more than the optimal level of capital ${ }^{5}$. Since good units have better investment opportunities, their managers have higher expected utility than managers of bad units. As a result, they do not want to lose their jobs and there is no need for the headquarters to overinvest in good divisions. The lower enjoyment of the cash flow by divisional managers, however, makes managers of good divisions willing to misallocate the capital provided by the headquarters and invest it in bad projects in order to reduce their own effort. To reduce the benefit of such investment misallocation towards bad projects, the headquarters should provide good divisions with less

\footnotetext{
2 Villalonga (2004a) also shows that unrelated diversification usually results in diversification discount while related diversification leads to diversification premium.

${ }^{3}$ Graham, Lemmon and Wolf (2002) also show that the method used by Berger and Ofek (1995) if applied to the dataset used by Graham, Lemmon and Wolf (2002) will predict a substantial diversification discount.

${ }^{4}$ Villalonga (2004b) also documented the diversification discount but only at $15 \%$ significance level.

${ }^{5}$ This result is similar to the result of Scharfstein and Stein (2000)
} 
than the optimal level of capital. Such investment misallocation among divisions (or cross-subsidization) can destroy the value of diversification.

If the diversification synergy is large enough, diversification may be value-creating. However, since good units have better investment opportunities, an underinvestment in a good unit reduces its value more than the overinvestment of the same magnitude reduces the value of a bad unit. Therefore, when the difference in investment opportunities between good and bad units is large enough, the investment misallocation among divisions destroys the value of good divisions more than the value of bad divisions. Hence, when the diversification synergy is not too large, a conglomerate with high ratio of bad to good divisions may be value-creating, while a conglomerate with low bad/good divisions ratio may be value-destroying. As a result, only bad single segment firms will decide to form a conglomerate and this decision will increase their combined value.

In this paper we distinguish the "observed diversification discount", i.e., a discount that one can observe if one fails to control for the self-selection bias in firm's decision to diversify, from the "real diversification discount", i.e., a discount that one can observe after eliminating the self-selection bias by a proper choice of the reference portfolio. By taking this difference into account, one may conclude that newly formed conglomerates should be traded at the real diversification premium (i.e., at a premium relative to the portfolio of similar single segment firms). However, since only bad firms choose to diversify, the value of a newly formed conglomerate will be lower than the value of a portfolio of all single segment firms (both good and bad) on the market. So, if one does not take into account the self-selection bias in firms' decision to diversify, one may find that new conglomerates are traded at the observed diversification discount. ${ }^{6}$

Over time divisions change their type (from bad to good and vise versa). Since newly formed conglomerates have a high bad/good divisions' ratio, this ratio will decline as time goes on. Each time, when one of the bad divisions becomes a good one, the value of the conglomerate will increase and the observed diversification discount will be reduced simply because of an improvement in investment opportunities ${ }^{7}$. There will be a simultaneous increase in the aggregate cost of cross-subsidization and, as a result, an increase in the true diversification discount (or, equivalently, a reduction in the true diversification premium). To avoid this destruction of value shareholders of the conglomerate would like to divest the good division but, due to the asymmetric information on the market they cannot receive the full price for it and, therefore, will have to keep it. Since any unit can change its type according to the exogenously determined stochastic rule (which is the same for all units), the ratio of good/bad divisions in the conglomerate will converge to the ratio of good/bad single segment firms on the market and the cost of investment misallocation among divisions can become severe enough, so it can offset the diversification synergy in the long run. Because of the asymmetric information problem, the conglomerate cannot divest good divisions ${ }^{8}$ and, therefore, old conglomerates will be value destroying and will be traded at the real diversification discount. However, the observed diversification discount for old conglomerates will be lower than for new conglomerates, which implies that the true and observed diversification discounts are negatively correlated. This, in particular, implies that conglomerates that appear to be the most successful ones are the most value destroying, and their value can be further increased by taking them apart.

Therefore, this paper provides an explanation for why single segment firms choose to diversify and what prevents conglomerates from value-increasing divestitures. Consistent with the self-selection evidence, the paper

\footnotetext{
${ }^{6}$ This result is consistent with Graham, Lemmon and Wolf (2002) funding that the market reacts positively on the diversifying acquisitions' announcements even when Berger and Oftek's (1995) method (that does not take self-selection into account), if applied to the same data set, predicts a diversification discount.

7 This result may be consistent with the empirical finding of Bevelander (2002), who shows that controlling for conglomerate's age decreases observed diversification discount. Although Bevelander (2002) defines conglomerate's age as a time since its main divisions went public and not as a time since conglomerate is formed, these two measures are positively correlated. This result is also consistent with the Berger and Ofek (1996) finding that the observed diversification discount decreases for a sample of conglomerated that existed during the time period from 1984 to 1987.

${ }^{8}$ If conglomerate were able to divest some or all of its good divisions, e.g., by incurring some cost to inform the market about its divisions' types, such divestitures would increase the combined conglomerate's value. This result would be consistent with the findings of Coment and Jarell (1995), John and Ofek (1995), and Berger and Ofek (1996) who show that refocusing divestitures leads to a positive market reaction.
} 
argues that at the time of conglomerate formation only bad single segment firms decide to diversify and such diversification is value-enhancing. It also argues that the cost of internal capital market inefficiency increases during the life of the conglomerate and such an increase results in the value destruction by old conglomerates. Asymmetric information precludes investors from valuing conglomerate divisions correctly and makes a value-increasing refocusing divestiture of good divisions too costly for the conglomerate's shareholders.

The paper provides several testable implications. First, it argues that the true diversification discount increases while the observed diversification discount decreases during the life of the conglomerate. Second, it predicts a negative relationship between the true and observed diversification discounts which implies that the most successful conglomerates are the most value-destroying ones and their value can be increased by refocusing divestitures. Third, since investment opportunities are greatly reduced during economic recessions and the true diversification discount positively depends on the good/bad divisions' ratio, one can expect conglomerates to have higher true diversification premiums during recessions and more refocusing activities during booms.

The rest of the paper is organized as the following: Part 2 presents a setup of the model, Part 3 solves for the equilibrium, Part 4 discusses some of the model's empirical predictions, Part 5 concludes.

\section{MODEL}

\section{$\underline{\text { Technology }}$}

Consider an economy of infinite number of conglomerates and single segment firms. A unit, defined as a single segment firm or as a division of a conglomerate, can be one of two types: bad or good. Each unit is run by a manager.

At any period $t$ managers of bad units have access to a "bad" project, while managers of good units have access to both "bad" and "good" projects. At the end of each period any unit can change its type with small probability $\varepsilon$ which does not depend on the unit's nature or on any agent's actions. At any period a manager can implement only one project. To generate cash flow the bad project requires capital investment only, while the good project requires both capital investment and the manager's effort. Given an investment level of $I$ at the beginning of the period, and, if this project is "good", an effort level of $e(I)$ from the manager, project $k \in\{$ bad, good $\}$ at the end of the same period generates a cash flow of

$$
f_{k}(I)=2 s_{k} \sqrt{I}
$$

where $s_{b}<s_{g}$. For simplicity, assume that $e(I)=I$. To avoid a trivial solution we also assume that the difference between marginal returns on capital for good and bad projects is high enough so that there is an equilibrium in which shareholders want the manager of a good unit to choose the good project. In particular, we assume that

$$
\frac{s_{g}}{s_{b}}>1+\frac{\alpha}{2 \theta^{f}}\left(\frac{\theta^{f}}{\theta^{d}}\right)^{2},
$$

where $\alpha, \theta^{f}$, and $\theta^{d}$ are the parameters of the managers' utility functions discussed below. In addition to cash flows from projects, we assume that conglomeration has additional benefits ${ }^{9}$ that result in an additional cash flow of

\footnotetext{
${ }^{9}$ For example, diversified firms can save on administrative costs. Lower probability of bankruptcy, which comes from diversified cash flows, may help to reduce the cost of debt or the debt capacity, which, in turns, leads to the larger tax shield (Lewellen (1971) and Berger and Ofek (1995)). An asymmetry of the tax law that does not permit having negative taxes in the case when firms experience losses may lead to the lower expected tax payments by diversified firms.
} 
$S(n)$, where $n$ is the number of divisions in the conglomerate and $S(n)$ is a concave synergy function so that the marginal benefit of diversification decreases with the size of the conglomerate.

\section{Objective functions}

Assume that the manager's utility is positively related to the cash flow produced by his unit and negatively related to the effort that he exerts towards the project. In addition, since managers of single segment firms are more independent than divisional managers, they can have greater control over the cash flows produced by their firms, and, therefore, their enjoinment of the cash flow is higher than the enjoinment of divisional managers. Therefore, assume that the utility function of a manager at any period $t$ is given by

$$
U=\theta \cdot f-\alpha \cdot e
$$

where $f$ is the unit's cash flow, $\alpha>0$ is the marginal cost of effort, $\theta=\theta^{f}$ for managers of single segment firms, $\theta=\theta^{d}$ for divisional managers in a conglomerate, and $\theta^{f}>\theta^{d}$. To avoid a trivial case when managers of good units always prefer to invest in the good project, assume that the cost of effort is high enough to generate the conflict of interests between the manager and the shareholders, namely, assume that

$$
\frac{\alpha}{\theta_{f}}>2 \text {. }
$$

Assume also that shareholders want to maximize their profit which is equal to the firm's cash flow less the cost of investment and that the compensation contract is incomplete, i.e., similar to the result of Scharfstein and Stein (2000), assume that no compensation contract is available and all managers derive their utility only from their units' cash flows.

\section{Information, labor market, and timeline}

The type of any single segment firm is observable to everybody while the type of any division is observable to its manager and the conglomerate's shareholders only. This may be the case, for example, because the market can observe the cash flows produced by each of the single segment firms but can observe only the aggregate cash flow produced by the conglomerate. Each period the headquarters ${ }^{10}$ provide each unit's manager with some capital investment and then the manager decides which project to implement. This decision is observable by the headquarters but they cannot overrule it. Based on the manager's decision, the headquarters may fire him in which case they will have to hire a new one. There is a competitive labor market for managers of bad single segment firms, so that any manager can find a job at a bad single segment firm. However, since good units generate higher cash flows than bad units, in the equilibrium the manager's utility in a good unit is higher than in a bad unit, and, therefore, no one would like to quit his job in a good unit. As a result, it is much harder to find a job in a good single segment firm or division and, for simplicity, we assume that it is impossible. At any period $t$ the sequence of events is the following:

1) Acquisition and divestiture decisions are made.

2) Headquarters provide managers with the capital investment.

3) If the manager is not satisfied with the investment level, he quits his job and immediately finds a new job at a bad single segment firm.

4) Managers of good units make decisions about which project to implement.

5) Cash flows are realized.

6) Based on the manager's decision in (4) the headquarters decide whether or not to fire the manager.

7) Each unit changes its type with probability $\varepsilon$

${ }^{10}$ Assume that the headquarters always behave in the best interests of the shareholders. 


\section{SOLVING FOR THE EQUILIBRIUM}

In the absence of the principal-agent conflict (i.e., when shareholders can prevent managers from quitting their jobs and ensure managers of good units to choose the good project), the investment level that maximizes shareholders' profit is equal to $I_{b}^{*}=s_{b}^{2}$ in bad units and $I_{g}^{*}=s_{g}^{2}$ in good units. We will refer to these investment levels as "optimal" investment levels and will look for a pure strategy equilibrium in which managers of good units invest in good projects.

\section{Capital allocation in single segment firms}

Let $u_{g}^{f}$ and $u_{b}^{f}$ be the present values of the managers' equilibrium expected utilities in good and bad single segment firms respectively. Denote $I_{b}^{f}$ and $I_{g}^{f}$ to be the equilibrium levels of investment in these firms. Given production function (1) and the manager's utility function (3), $u_{b}^{f}$ and $u_{g}^{f}$ can be written as

$$
\left.\begin{array}{l}
u_{b}^{f}=\theta^{f} 2 s_{b} \sqrt{I_{b}^{f}}+\delta \varepsilon u_{g}^{f}+\delta(1-\varepsilon) u_{b}^{f} \\
u_{g}^{f}=\theta^{f} 2 s_{g} \sqrt{I_{g}^{f}}-\alpha I_{g}^{f}+\delta \varepsilon u_{b}^{f}+\delta(1-\varepsilon) u_{g}^{f}
\end{array}\right\}
$$

where the last two terms in each equation above represent the present value of the manager's expected utility in future periods and the remaining terms represent the manager's utility in the current period.

Since there is no principal-agent conflict in bad firms, the investment level in a bad single segment firm is optimal, i.e., $I_{b}^{f}=I_{b}^{*}=s_{b}^{2}$. The manager of a good single segment firm can misallocate the investment towards the bad project in order to reduce his effort. There are two ways in which the shareholders can prevent the manager from this investment misallocation. First, they can adjust the amount of capital they provide to the manager, and, second, they can fire a manager who misallocates the investment. In particular, let us look for an equilibrium in which shareholders of good single segment firms provide the manager with $I_{g}^{f}$ of investment capital (where $I_{g}^{f}$ is yet to be determined) and fire him if he chooses the bad project. If the manager decides to invest in the bad project, he will receive $2 \theta^{f} s_{b} \sqrt{I_{g}^{f}}$ utility in the current period, get fired, find a job in a bad single segment firm and, thus, the present value of his future utility will be $\delta u_{b}^{f}$. Therefore, the optimization program for shareholders of good single segment firms can be written as:

$$
\begin{aligned}
& \max _{I_{g}^{f}}\left\{2 s_{g} \sqrt{I_{g}^{f}}-I_{g}^{f}\right\}, \\
& \text { s.t. } \quad \text { IC: } u_{g}^{f} \geq\left(2 \theta^{f} s_{b} \sqrt{I_{g}^{f}}+\delta u_{b}^{f}\right),
\end{aligned}
$$

IR: $u_{g}^{f} \geq u_{b}^{f}$,

where $u_{b}^{f}$ and $u_{g}^{f}$ are functions of $I_{g}^{f}$ defined by (5).

Since the difference between good and bad projects is big enough ((2) is satisfied), one can expect that managers of good firms never quit their jobs voluntarily, and, thus the Individual Rationality (IR) constraint (6c) is 
not binding. Note also that the Incentive Compatibility (IC) constraint (6b) is violated when $I_{g}^{f}$ is high, and this imposes an upper boundary on the equilibrium level of investment in a good single segment firm. The value of this boundary depends on how high the manager's cost of effort $\alpha$ is relative to his enjoinment of the cash flow $\theta^{f}$. Indeed, if the investment level is high enough, the cost of effort overweights the benefits of a higher cash flow and, therefore, the manager has an incentive to reduce his effort by choosing the bad project. So, when the marginal cost of efforts $\alpha$ is high (i.e., (4) is satisfied), the optimal investment level in good single segment firms $I_{g}^{*}$ cannot be achieved and shareholders have to reduce the investment level. The following theorem summarizes the discussion above.

\section{Theorem 1}

The investment level in bad single segment firms $I_{b}^{f}$ is optimal and is equal to $I_{b}^{*} \equiv s_{b}^{2}$ while the investment level in good single segment firms is less than the optimal, i.e., $I_{g}^{f}<I_{g}^{*} \equiv s_{g}^{2}$

Proof: See appendix.

\section{Capital allocation in conglomerates}

The principal-agent problem in a conglomerate is twofold. First, shareholders need to prevent managers of bad divisions from quitting their jobs and going to single segment firms where the utility they receive from the cash flow is higher. Second, shareholders want to prevent managers of good divisions from investing in bad projects.

Similar to the case of single segment firms, let $u_{b}^{d}$ and $u_{g}^{d}$ be the present values of the managers' equilibrium expected utilities in bad and good divisions respectively and let $I_{b}^{d}$ and $I_{g}^{d}$ be the equilibrium levels of investment in these divisions. By the same logic, $u_{b}^{d}$ and $u_{g}^{d}$ can be written as

$\left.\begin{array}{l}u_{b}^{d}=\theta^{d} 2 s_{b} \sqrt{I_{b}^{d}}+\delta \varepsilon u_{g}^{d}+\delta(1-\varepsilon) u_{b}^{d} \\ u_{g}^{d}=\theta^{d} 2 s_{g} \sqrt{I_{g}^{d}}-\alpha I_{g}^{d}+\delta \varepsilon u_{b}^{d}+\delta(1-\varepsilon) u_{g}^{d}\end{array}\right\}$.

Thus, shareholders' optimization program for good divisions can be written as

$\max _{I_{g}^{d}}\left\{2 s_{g} \sqrt{I_{g}^{d}}-I_{g}^{d}\right\}$

s.t. $\quad$ IC: $u_{g}^{d} \geq\left(2 \theta^{d} s_{b} \sqrt{I_{g}^{d}}+\delta u_{b}^{f}\right)$,

IR: $u_{g}^{d} \geq u_{b}^{f}$,

where $u_{b}^{d}$ and $u_{g}^{d}$ are functions of $I_{b}^{d}$ and $I_{g}^{d}$ defined by (7).

Similar to the case of single segment firms, when the difference between good and bad projects is big enough ((2) is satisfied) the IR constraint (8c) is not binding. The lower enjoinment of cash flow $\theta^{d}<\theta^{f}$ makes the IC constraint (8b) more binding than in the case of single segment firms, and, therefore, makes managers more willing to choose the bad project. To prevent this, shareholders need to reduce the investment in good divisions. 
Therefore, one should expect an underinvestment in good divisions, i.e., $I_{g}^{d}<I_{g}^{f}$. Substituting this inequality into binding IC constraints $(6 \mathrm{~b})$ and $(8 \mathrm{~b})$ one can find $u_{g}^{f}>u_{g}^{d}$, i.e., the expected utility of a manager of a good division is less than that of a manager of a good single segment firm.

Since managers of bad divisions can implement only bad projects, they cannot misallocate the investment. Therefore, the shareholders' optimization program for bad divisions does not include the IC constraint and can be written as

$$
\max _{I_{b}^{d}}\left\{2 s_{b} \sqrt{I_{b}^{d}}-I_{b}^{d}\right\}
$$

s.t.: $\quad$ IR: $u_{b}^{d} \geq u_{b}^{f}$.

Using (7) and the fact that $u_{g}^{f}>u_{g}^{d}$, one can show that the IR constraint (9b) is binding, and, therefore, in the equilibrium $u_{b}^{f}=u_{b}^{d}$. Since $u_{g}^{f}>u_{g}^{d}$ and $\theta^{f}>\theta^{d}$, to satisfy the IR constraint, shareholders need to increase investment in bad divisions. As a result, one should expect an overinvestment in bad divisions, i.e., $I_{b}^{d}>I_{b}^{f}$. The following theorem ${ }^{11}$ characterizes the investment levels in good and bad divisions.

\section{Theorem 2}

There is an overinvestment in bad divisions (relative to the bad single segment firms and the optimal level) and there is an underinvestment in good divisions (relative to the bad single segment firms and the optimal level), i.e, $I_{b}^{f}>I_{b}^{d}=I_{b}^{*}$ and $I_{g}^{f}<I_{g}^{d}<I_{g}^{*}$.

Proof: See appendix.

The size of a conglomerate

Theorems 1 and 2 characterize the equilibrium investment levels in external and internal capital markets. To complete the description of the general equilibrium in the model we need to understand which firms choose to diversify and how the value of a conglomerate and the diversification discount evolve over time.

To analyze how diversification affects the firm's value, let define

$$
\Delta_{b}=2 s_{b}\left(\sqrt{I_{b}^{f}}-\sqrt{I_{b}^{d}}\right)-\left(I_{b}^{f}-I_{b}^{d}\right)
$$

And

$$
\Delta_{g}=2 s_{g}\left(\sqrt{I_{g}^{f}}-\sqrt{I_{g}^{d}}\right)-\left(I_{g}^{f}-I_{g}^{d}\right)
$$

to be the differences between equilibrium profits of a single segment firm and a division of the same type (without taking synergy into account). Since $s_{g}>s_{b}$, it is reasonable to assume that $\Delta_{g}>\Delta_{b}$. The following Lemma

\footnotetext{
${ }^{11}$ This theorem is consistent with the empirical findings of Rajan, Servaes and Zingales (2000), Scharfstein (1998), Lamont (1997) and Shin and Stulz (1998).
} 
proves that $\Delta_{g}>\Delta_{b}$ is true at least when the difference in utility functions of managers of singe segment firms and divisions is not too large (i.e., when $\theta_{g}-\theta_{b}$ is small enough).

\section{Lemma 1:}

If $\theta_{g}-\theta_{b}$ is small, then $\Delta_{g}>\Delta_{b}$.

Proof: see appendix.

Taking the equilibrium investment levels $I_{b}^{d}$ and $I_{g}^{d}$ as given, each period shareholders need to make acquisition and divestiture decisions. Since $\Delta_{g}>\Delta_{b}$, shareholders of a conglomerate never want to acquire a good single segment firm. Furthermore, since the market cannot observe the type of the divested division it believes that any divested division is bad and prices it based on these beliefs. As a result, a conglomerate will never be able to divest a good division.

A conglomerate that consists of $n_{b}$ bad divisions and $n_{g}$ good divisions produces a synergy of $S\left(n_{b}+n_{g}\right)$, and destroys $\Delta_{g} n_{g}+\Delta_{b} n_{b}$ in value due to the capital misallocation problem. Therefore, the net value destruction by a conglomerate (the true diversification discount) is given by

$D\left(n_{b}, n_{g}\right)=\frac{1}{1-\delta}\left(\Delta_{b} n_{b}+\Delta_{g} n_{g}-S\left(n_{b}+n_{g}\right)\right)+o(1)$

where $o(1)$ is an infinitesimal variable that reflects the small probability $\varepsilon$ that some units will change their types in the future. Since shareholders of a conglomerate do not want to acquire good single segment firms and cannot divest good divisions, for any given number of good divisions the shareholders want to minimize the true diversification discount by adjusting the number of bad divisions through acquisitions or divestitures. Therefore, their optimization problem can be written as:

$$
\min _{n_{b}}\left\{D\left(n_{b}, n_{g}\right)\right\}
$$

It follows from (11) and (12) that at any period $t$ the optimal number of divisions (denoted by $n^{*}$ ) can be determined by

$$
\frac{d S(n)}{d n}=\Delta_{b} .
$$

For a conglomerate that consists of $n_{b}$ bad divisions and $n_{g}=n^{*}-n_{b}$ good divisions the true diversification discount is equal to

$D\left(n_{b}, n^{*}-n_{b}\right)=\frac{1}{1-\delta}\left(\Delta_{g} n^{*}-\left(\Delta_{g}-\Delta_{b}\right) n_{b}-S\left(n^{*}\right)\right)+o(1)$

and decreases with the number of bad divisions. In particular, since at the time of its formation the conglomerate consists only out of bad divisions, the diversification discount is equal to 
$D\left(0, n^{*}\right)=\frac{1}{1-\delta}\left(\Delta_{b} n^{*}-S\left(n^{*}\right)\right)+o(1)$. The conglomerate will be formed if and only if the conglomeration is value-enhancing, i.e., if and only if the real diversification discount is negative, i.e. $D\left(0, n^{*}\right)<0$ or, alternatively, if and only if there is some $n \geq 2$ such that the average (per division) synergy is greater than agency costs in a bad division, i.e.,

$$
\frac{S(n)}{n}>\Delta_{b}
$$

Once the conglomerate is formed, for each period there is a probability $\varepsilon$ that any division will change its type. Since (i) the probability of type change $\varepsilon$ is the same for all divisions and independent firms; (ii) the newly formed conglomerate consists of bad divisions only; (iii) condition (13) implies that the number of divisions in a conglomerate is bounded from above; and (iv) the conglomerate cannot divest good divisions, over time the ratio of bad to good divisions in a conglomerate will converge to the ratio of bad to good single segment firms in the market, which is equal to $1 / 2$ in the steady state. Thus, old conglomerates will consist of $n_{b}=\frac{n^{*}}{2}$ bad and $n_{g}=\frac{n^{*}}{2}$ good divisions and their diversification discounts will be equal to

$$
D\left(\frac{n^{*}}{2}, \frac{n^{*}}{2}\right)=\frac{1}{1-\delta}\left(\left(\frac{\Delta_{g}+\Delta_{b}}{2}\right) n^{*}-S\left(n^{*}\right)\right)+o(1) . \text { Therefore, if the average (per-division) }
$$

synergy is less than the average (per-division) agency cost for conglomerates with the same ratio of bad to good divisions as the ratio of bad to good single segment firms in the market, i.e., if

$$
\frac{S\left(n^{*}\right)}{n}<\frac{\Delta_{b}+\Delta_{g}}{2}
$$

where $n^{*}$ is determined by (13), then we can conclude that old conglomerates destroy value. The discussion above can be summarized in the following theorem:

\section{Theorem 3:}

Only bad single segment firms choose to diversify. The diversification happens if and only if the synergy from it is large enough so that condition (15) holds. The conglomeration is profitable when it happens and there is a real diversification premium for new conglomerates. Over time the real diversification premium decreases and, if the synergy is not too high (condition (16) holds) then there is a real diversification discount for old conglomerates.

\section{$4 \quad$ EMPIRICAL IMPLICATIONS}

One should differentiate between the real and observed diversification discounts. The real diversification discount is defined as the difference between the value of a conglomerate and the combined value of its division if divested. Thus, the real diversification discount measures the value destroyed by diversification. The observed diversification discount is defined as the difference between the value of a conglomerate with $n$ divisions and the value $n$ average single segment firms. Thus, the observed diversification discount may be affected by the selfselection bias in firms' decisions to diversify and is not a proper measure of value destruction. Let us define $V_{b}=\frac{1}{1-\delta}\left(f_{b}\left(I_{b}^{f}\right)-I_{b}^{f}\right)+o(1)$ and $V_{g}=\frac{1}{1-\delta}\left(f_{g}\left(I_{g}^{f}\right)-I_{g}^{f}\right)+o(1)$ to be the values of bad and good 
single segment firms. In this case, the observed diversification discount for a conglomerate that consists of $n_{b}$ bad and $n_{g}=n^{*}-n_{b}$ good divisions is equal to

$$
\begin{gathered}
\tilde{D}\left(n_{b}, n_{g}\right)=\frac{1}{1-\delta}\left\{\left(V_{b} \frac{n^{*}}{2}+V_{g} \frac{n^{*}}{2}\right)-\left(V_{b} n_{b}+V_{g} n_{g}-D\left(n_{b}, n_{g}\right)\right)\right\}+o(1)= \\
=\frac{1}{1-\delta}\left\{\left(V_{b}-V_{g}+\Delta_{g}\right) \frac{n^{*}}{2}+S\left(n^{*}\right)+\left(\left(V_{g}-\Delta_{g}\right)-\left(V_{b}-\Delta_{b}\right)\right) n_{b}\right\}+o(1) .
\end{gathered}
$$

If the difference between good and bad units is large enough (condition (2) holds), then there is an observed diversification discount for almost all conglomerates ${ }^{12}$ (i.e., $\widetilde{D}\left(n_{b}, n_{g}\right)>0$ for $n_{b} \geq n_{g}$ ) and the observed diversification discount decreases with the number of bad divisions. The discussion above, together with Theorem 3 , can be summarized in the following result.

\section{Result 1}

Observed and real diversification discounts are negatively correlated and almost all conglomerates are traded at an observed diversification discount.

One of the important implications of Result 1 is that the conglomerates that appear to be the most successful and are traded at high observed premiums are the most value destroying and have the highest real diversification discounts. On contrary, the conglomerates that appear to be the worst performers, have a lot of bad divisions, and are traded at observed diversification discounts are the most efficient ones and have substantial real diversification premiums.

The discussion prior to Theorem 3 implies that the ratio of bad to good divisions and, thus, the number of bad divisions decreases with the age of a conglomerate. Therefore, the observed diversification discount should decrease with the conglomerate's age as well. Furthermore, since the ratio of bad to good divisions in the conglomerate converges to the ratio of bad to good single segment firms in the market, the difference between the true and observed diversification discounts converges to zero over time. Therefore, the following is true.

\section{Result 2}

The observed diversification discount is higher and the true diversification discount is lower for newly formed conglomerates than for old conglomerates. In addition, the true and observed diversification discounts are the same for old conglomerates.

Result 2 is consistent with the empirical finding of Bevelander (2002), who shows that controlling for conglomerate's age decreases observed diversification discount. Although Bevelander (2002) defines conglomerate's age as a time since its main divisions went public and not as a time since conglomerate is formed, these two measures are positively correlated. The descriptive statistic presented by Berger and Ofek (1996) also lies in line with this result. In their study Berger and Ofek (1996) collect a data for a sample of conglomerates that existed during 1984-1987 period and document the decrease in the average observed diversification discount for these conglomerates.

\footnotetext{
${ }^{12}$ With the possible exceptions of a small number of conglomerates in which the ration of good/bad divisions is higher than the ratio of good/bad firms in the market. In particular, if there is an infinite number of divisions in each conglomerate, the number of conglomerates in which the ration of good/bad divisions is higher than the ratio of good/bad firms in the market is infinitesimal.
} 
Now, consider the effect of an economy-wide shock on a conglomerate. Define a good shock (a "boom") to be a one-time increase in the probability that the type of unit will change from bad to good. Define a bad shock (a "recession") to be a one-time increase in the probability that the type of unit will change from good to bad. Consider the effect of these shocks on a conglomerate that was previously in a steady state (i.e., had the same ratio of good to bad divisions as the ratio of good to bad firms in the market). Since a shock affects single segment firms and divisions in the same way, the ratio of good to bad divisions for such a conglomerate will remain equal to the ratio of good to bad firms on the market at any time after the shock. As a result, the true and observed diversification discounts will remain equal to each other. Furthermore, since the capital misallocation problem is more severe in good divisions and, thus, the true diversification discount positively depends on the number of good divisions, the following is true.

\section{Result 3}

Conglomerates have the highest true diversification premiums during economic recessions and the highest true diversification discounts during economic booms.

Up to this point we have assumed that the market cannot observe the type of individual division in a conglomerate. This assumption implies that the price of any divested division will be equal to the value of a bad single segment firm which makes it impossible for a conglomerate to divest a good division. Now let us relax this assumption and assume that the conglomerate can reveal types of its divisions ${ }^{13}$ for a nominal revelation cost of $R$. Thus, shareholders of the conglomerate will decide to refocus when the true diversification discount is greater than the revelation cost $R$, i.e., when $D\left(n_{b}, n^{*}-n_{b}\right)>R$. Since the true diversification discount increases with the number of good divisions, the following result is true:

\section{Result 4}

There are more refocusing activities during economic booms.

Now, let us look at diversification and divestiture activities of a single conglomerate in the absence of economy-wide shocks. In order to do that, let us alter the assumption that the synergy function $S(n)$ depends only on the total number of divisions and assume that it depends on the relative number of bad and good divisions as well, i.e., assume that the synergy is equal to $\hat{S}\left(n, n_{g}\right)=S(n) \lambda\left(n_{g}\right)$, and, keeping the total number of divisions constant, the total synergy is lower for conglomerates with a higher ratio of good to bad divisions, i.e.,

$$
\frac{\partial \hat{S}\left(n, n_{g}\right)}{\partial n_{g}} \equiv S(n) \frac{d \lambda\left(n_{g}\right)}{d n_{g}}<0 .
$$

One of the rationales for assumption (18) lies in the possible benefits of the diversification (not modeled in this paper). Namely, one of the benefits of diversification is the access to the internal capital market which allows implementing profitable projects when external financing is not available or is extremely costly (Fluck and Lynch (1999)). Therefore, if we assume that bad firms have less internal financing available then it would be reasonable to assume that the synergy of diversification is higher for bad divisions.

Similar to the base case, shareholders of a conglomerate do not want to acquire good single segment firms and cannot divest good divisions. Therefore, for any number of good divisions $n_{g}$ the total number of divisions is determined from

\footnotetext{
${ }^{13}$ The qualitative results will be the same if we assume that the conglomerate can reveal the types of some (not all) of its divisions where the cost of revelation is an increasing and concave function of the number of divisions which types are revealed.
} 


$$
\frac{d S(n)}{d n} \lambda\left(n_{g}\right)=\Delta_{b} .
$$

Conditions, (18) and (19) together imply that the total number of divisions negatively depends on the number of good divisions. Thus, when some of the bad divisions change their types, the marginal synergy decreases and the conglomerate needs to divest some divisions. The asymmetric information about divisions' types prevents the conglomerate from divesting a good division. As a result, the conglomerate needs to divest a bad division. Such divestiture, together with the preceding type change, leads to a higher true diversification discount and a lower observed diversification discount. Similarly, when some of good divisions change their types, the marginal synergy increases and the conglomerate acquires a new bad single segment firm. This type change and acquisition are accompanied by a decrease in the true diversification discount and by an increase in the observed diversification discount. Thus, the following result is true.

\section{Result 5}

A divestiture by a single conglomerate is accompanied by an increase in its value and a decrease in the observed diversification discount. However, it results in an increase in the value destroyed by the conglomerate (higher true diversification discount). Similarly, an acquisition by a single conglomerate is accompanied by a decrease in the conglomerate's value and an increase in the observed diversification discount but it results in a decrease in the true diversification discount.

Result 5 is consistent with Coment and Jarell (1995) who find the negative relationship between refocusing activities and the observed diversification discount and document a positive relationship between the observed discount and diversifying acquisitions. Since only bad single segment firms can be acquired and only good divisions can be divested, one can expect that the market value of the divested division will be substantially higher than its value before it was initially acquired. This result lies in line with Kaplan and Weisbach (1992) who show that the market price (adjusted to the S\&P 500 index) of a firm that was acquired and then divested is $43 \%$ higher after the divestiture than it was before the initial acquisition.

This paper presents a dynamic model of diversification and divestiture that takes into account the selfselection bias in firms' decisions to diversify and the existence of value-destroying internal capital market inefficiencies. By predicting the real diversification premium for newly formed conglomerates and the real diversification discount for old ones, the model helps to understand the reasons to diversify and not to divest afterwards even when the divestiture may increase the firm's value. Consistent with the self-selection evidence (Lang and Stulz (1999), Hyland (2002) and Chevalier (2004)), the model predicts that only bad firms will diversify and this diversification will increase their values. The failure to control for firms' types (good or bad), however, may lead to an underestimation of the diversification premium and to an observed diversification discount.

A more severe principal-agent problem in conglomerates results in an internal capital market inefficiency. Consistent with the evidence of conglomerate socialism (Rajan, Servaes and Zingales (2000), Scharfstein (1998), Lamont (1997) and Shin and Stulz (1998)), the model predicts an overinvestment in good divisions and an underinvestment in bad divisions. It argues that an underinvestment in good divisions is more costly than an overinvestment in bad ones. At the time a conglomerate is formed, the investment misallocation problem is not severe enough to overweight the benefits of diversification and the conglomeration is value-enhancing. Unfortunately, as time goes by, the ratio of good to bad divisions in the conglomerate increases. This leads to higher losses from investment misallocation and, at some point in time, these losses start to overweight the benefits of diversification and the diversification becomes unprofitable. The conglomerate cannot credibly reveal types of its divisions and, thus, cannot divest a good division at a fair price. As a result, old conglomerates will destroy value and will not be able to break themselves apart. A failure to control for the self-selection bias, however, can result in reporting a higher observed diversification discount for new conglomerates. One of the important implications of the real and observed diversification discount dynamics is that real and observed diversification discounts are negatively 
correlated. Saying it differently, this means that conglomerates that appear to be the most successful and are traded at a high observed premiums are, in fact, the most value destroying ones and have the highest real diversification discounts. On contrary, the conglomerates that appear to be the worst performers, have a lot of bad divisions, and are traded at an observed diversification discount are the most efficient ones and, in fact, have substantial real diversification premiums.

This paper also analyses how diversification and divestiture activities depend on the external shocks and how these shocks affect the value of a conglomerate and the diversification discount. The model predicts that refocusing activities and diversification discount are pro-cyclical.

\section{APPENDIX}

\section{Proof of Theorem 1}

Solving (5) for $u_{b}^{f}$ and $u_{g}^{f}$, using $I_{b}^{f}=s_{b}^{2}$, denoting $x=\sqrt{I_{g}^{f}}$, and using the fact that $\varepsilon$ is small, i.e., $\varepsilon=o(1)$ where $o(1)$ is infinitesimal variable, allows one to rewrite the IC constraint (6b) as

$A^{f}(x) \equiv-\frac{1}{1-\delta}\left(\alpha x^{2}-2 \theta^{f}\left(s_{g}-(1-\delta) s_{b}\right) x+2 \theta^{f} \delta s_{b}^{2}\right)+o(1) \geq 0$

At the optimal investment level $I_{g}^{f}=I_{g}^{*}=s_{g}^{2}$, i.e., at $x=s_{g}$, one can find

$A^{f}\left(s_{g}\right)=-\frac{1}{1-\delta}\left(\alpha s_{g}^{2}-2 \theta^{f}\left(s_{g}-s_{b}\right)\left(s_{g}+\delta s_{b}\right) x+2 \theta^{f} \delta s_{b}^{2}\right)+o(1)<0$

where the last inequality follows from (4). Similarly, at $x=s_{g}$ one can find

$$
\frac{d A^{f}(x)}{d x}\left(x=s_{g}\right)=-\frac{1}{1-\delta}\left(2 \alpha s_{g}-2 \theta^{f}\left(s_{g}-(1-\delta) s_{b}\right)\right)+o(1)<0
$$

where the last inequality follows from (4). Since $A^{f}(x)$ is a quadratic function, (A2) and (A3) implies that (A1) may be true only if $x<s_{g}$, i.e., only if $I_{b}^{f}<s_{b}^{2}$, and the solution to optimization program (6a)-(6c) is the largest solution to $A^{f}(x)=0$. Using (2) one can find

$$
A^{f}\left(s_{b}\right)=-\frac{s_{b}^{2}}{1-\delta}\left(\alpha-2 \theta^{f}\left(\frac{s_{g}}{s_{b}}-1\right)\right)+o(1)>0
$$

Therefore, a solution to $A^{f}(x)=0$ exists. In addition, (A4) implies that the IR constraint (6c) is satisfied.

\section{Proof of Theorem 2}

Similar to the proof of Theorem 1 , one can rewrite the IC constraint (8b) as 
$A^{d}(x) \equiv-\frac{1}{1-\delta}\left(\alpha x^{2}-2 \theta^{d}\left(s_{g}-(1-\delta) s_{b}\right) x+2 \theta^{f} \delta s_{b}^{2}\right)+o(1) \geq 0$,

where $x=\sqrt{I_{g}^{d}}$. Furthermore, $A^{d}(x)<A^{f}(x)$ and $\frac{d A^{d}(x)}{d x}<\frac{d A^{f}(x)}{d x}$ for any $x$. These inequalities, together with (A2) and (A3), imply that the solution to optimization program (8a)-(8c) is the largest solution to $A^{d}(x)=0$ and this solution (if exists) is smaller than the solution to optimization program (6a)-(6c). Using (2), one can find

$A^{f}\left(\frac{\theta^{f}}{\theta^{d}} s_{b}\right)=-\frac{s_{b}^{2}}{1-\delta}\left(\alpha\left(\frac{\theta^{f}}{\theta^{d}}\right)^{2}-2 \theta^{f}\left(\frac{s_{g}}{s_{b}}-1\right)\right)+o(1)>0$

which implies that a solution to $A^{d}(x)=0$ exists and the IR constraint (8c) is satisfied.

\section{Proof of Lemma 1}

$\xi=\theta^{f}-\theta^{d}$

to be an infinitesimal difference between utility functions of managers of single segment firms and divisions of conglomerates. The investment level in bad divisions is determined from the IR constraint (9b) and must satisfy:

$\frac{1}{1-\delta} 2 \theta^{f} \sqrt{I_{b}^{f}}+o_{\varepsilon}(1)=\frac{1}{1-\delta} 2 \theta^{d} \sqrt{I_{b}^{d}}+o_{\varepsilon}(1)$

where $o_{\varepsilon}(1)$ is an infinitesimal variable that reflects the fact that $\varepsilon$ is small (i.e., $o_{\varepsilon}(1)$ converges to zero when $\varepsilon$ converges to zero). Using $I_{b}^{f}=s_{b}^{2}$ and (A7), equation (A8) can be rewritten as

$I_{b}^{d}=\left(1+\frac{\xi}{\theta^{d}}\right)^{2} I_{b}^{f}+o_{\varepsilon}(1)$

Substituting $I_{b}^{f}=s_{b}^{2}$ and (A9) into (10a) allows one to find

$\Delta_{b}=2 s_{b}^{2} \frac{\xi}{\theta^{d}}-s_{b}^{2}\left(2 \frac{\xi}{\theta^{d}}+\left(\frac{\xi}{\theta^{d}}\right)^{2}\right)+o_{\varepsilon}(1)=o_{\xi}(\xi)+o_{\varepsilon}(1)$

where $o_{\xi}(1)$ is an infinitesimal variable of higher order than $\xi$, i.e., $\lim \frac{o_{\xi}(\xi)}{\xi}=0$. Since $\sqrt{I_{g}^{f}}$ and $\sqrt{I_{g}^{d}}$ are the largest solutions to $A^{f}(x)=0$ and $A^{d}(x)=0$ respectively, one may find that 


$$
\frac{d \sqrt{I_{g}^{d}}}{d \xi}=-\frac{\frac{\partial A^{d}(x, \xi)}{\partial \xi}}{\frac{\partial A^{d}(x, \xi)}{\partial x}}
$$

where $A^{d}(x)=-\frac{1}{1-\delta}\left(\alpha x^{2}-2\left(\theta^{f}-\xi\right)\left(s_{g}-(1-\delta) s_{b}\right) x+2 \theta^{f} \delta s_{b}^{2}\right)+o_{\varepsilon}(1)$. Therefore

$$
\frac{d \sqrt{I_{g}^{d}}}{d \xi}=\frac{\frac{2\left(s_{g}-(1-\delta) s_{b}\right) x}{1-\delta}}{\frac{\partial A^{d}(x, \xi)}{\partial x}}+o_{\varepsilon}(1)<0
$$

where the last inequality follows from the fact that $\frac{\partial A^{d}(x, \xi)}{\partial x}<0$ at the largest solution to $A^{d}(x, \xi)=0$. Using (A12), one can find

$$
\sqrt{I_{g}^{d}}=\sqrt{I_{g}^{f}}-k \xi+o_{\xi}(\xi)+o_{\varepsilon}(1)
$$

where $k=\frac{\frac{2\left(s_{g}-(1-\delta) s_{b}\right) x}{\frac{1-\delta}{\partial x}}}{\frac{\partial(x, \xi)}{\partial x}}+o_{\varepsilon}(1)<0$. Substituting (A13) into (10b) one can find

$$
\Delta_{g}=2 s_{g} k \xi\left(s_{g}-\sqrt{I_{g}^{f}}\right)+o_{\xi}(\xi)+o_{\varepsilon}(1)
$$

Since $2 s_{g} k\left(s_{g}-\sqrt{I_{g}^{f}}\right)<0$, for a small negative $\xi$ we have $\Delta_{g}>\Delta_{b}$.

\section{AUTHOR INFORMATION}

Yuri Khoroshilov is an Assistant Professor of Finance at the University of Ottawa Telfer School of Management. He has received his Ph.D. in Finance degree from Stephen M. Ross School of Business, University of Michigan in May 2005. He also has a Master in Economics degree from the University of Michigan, Ann Arbor, and a bachelor degree in Mathematics from the Moscow State University, Russia. His current research interests include behavioral economics and finance, experimental economics and finance, auction theory, and optimal contract design.

\section{REFERENCES}

1. Berger, P. and E. Ofek, 1995, "Diversification's effect on firm value," Journal of Financial Economics 37, 39-65.

2. Berger, P. and E. Ofek, 1996, "Bustup takeovers of value destroying diversified firms", Journal of Finance, 51, 1175-1200.

3. Berkovitch, E., Israel, R. and Tolkowsky, E., 2001, "The boundaries of the firm: the choice between standalone and integrated firms," Working paper, Tel Aviv University.

4. Bevelander, J., 2002, “Tobin's q, corporate diversification and Firm age," Working paper, MIT. 
5. Burch, T., V. Nanda and M.P. Narayanan, 2004, "Industry structure and the conglomerate discount: theory and evidence," Working paper, University of Michigan.

6. Chevalier, J., 2004, "What do we know about cross-subsidization? Evidence from merging firms," Advances in Economic Analysis and Policy, 4(1).

7. Comment, R. and G. Jarrell, 1995, “Corporate focus and stock returns," Journal of Financial Economics, 37, 67-87.

8. $\quad$ Fluck, Z. and A. Lynch, 1999, "Why do firm merge and then divest? A theory of financial synergy," Journal of Business 72, 319-346.

9. Goel, A., V. Nanda and M.P. Narayanan, 2000, "Resource allocation in conglomerates under moral hazard," Working paper, University of Michigan.

10. Graham, J., M. Lemmon and J. Wolf, 2002, “Does corporate diversification destroy value?” Journal of Finance 57 (2). p 695-720.

11. Hyland, D., 2002, "Why firms diversify: an empirical examination," Financial Management, 31 (1). p 5181.

12. John, K. and E. Ofek, 1995, “Asset sales and increase in focus", Journal of Financial Economics, 37, 105126.

13. Kaplan, S. and M. Weisbach, 1992, "The Success of Acquisitions: Evidence from Divestitures," Journal of Finance 47, 107-138.

14. Lamont, O., 1997, "Cash flow and investment: Internal capital markets evidence," Journal of Finance 52, 83-109.

15. Lamont, O. and C. Polk, 2002, "Does diversification destroy value? Evidence from industry shocks," Journal of Financial Economics,. 63 (1). p 51-77.

16. Lang, L. and R. Stulz, 1994, "Tobin's q, corporate diversification and firm performance," Journal of Political Economy 102, 1248-1280.

17. Lewellen, W., 1971, "A pure financial rationale for the conglomerate merger," Journal of Finance 26, 521537.

18. Maksimovic, V. and G. Phillips, 2002, "Do Conglomerate Firms Allocate Resources Inefficiently Across Industries? Theory and Evidence," Journal of Finance, 57, 721-767.

19. Rajan, R., H. Servaes and L. Zingales, 2000, "The cost of diversity: The diversification discount and inefficient investment," Journal of Finance, 55 (1). p 35-80.

20. Scharfstein, D., 1998, "The dark side of internal capital markets II: evidence from diversified conglomerates," NBER working paper 6352.

21. Scharfstein, D. and J. Stein, 2000, "The dark side of internal capital markets: divisional rent-seeking and inefficient investment," Journal of Finance, 55 (6). p 2537-64.

22. Servaes H., 1996, "The value of diversification during the conglomerate merger wave," Journal of Finance 51, 1201-1225.

23. Shin, H. and R. Stulz, 1998, “Are internal capital markets efficient?” Quarterly Journal of Economics 113. 531-552.

24. Stein J., 1997, "Internal capital markets and the competition for corporate resources," Journal of Finance $52,111-133$.

25. Villalonga, B. 2004a, "Diversification Discount or Premium? New Evidence from the Business Information Tracking Series," Journal of Finance 59, 479-506.

26. Villalonga, B. 2004b, "Does Diversification Cause the Diversification Discount," Financial Management 33, 5-27. 
NOTES 